\title{
Disponibilidad y potencial energético de la biomasa del bosque nativo para el desarrollo de la dendroenergía en el centro-sur de Chile
}

\author{
Biomass stock and potential energy for the dendroenergy development based on native forests \\ of south-central Chile
}

\author{
Adison Altamirano a*, Bastienne Schlegel b, Óscar Thiers ${ }^{\mathrm{c}, \mathrm{d}}$, Alejandro Miranda a,b, \\ Bernardo Pilquinao ${ }^{\text {bee }}$, Raúl Orrego ${ }^{\mathrm{f}}$, Carola Rocha ${ }^{\mathrm{b}}$ \\ *Autor de correspondencia: ${ }^{a}$ Universidad de La Frontera, Departamento de Ciencias Forestales, \\ Laboratorio de Ecología del Paisaje Forestal, Temuco, Chile, tel.: 56-45-2325658, adison.altamirano@ufrontera.cl \\ b Universidad Austral de Chile, Facultad de Ciencias Forestales y Recursos Naturales, Escuela de Graduados, Valdivia, Chile. \\ ${ }^{c}$ Universidad Austral de Chile, Facultad de Ciencias Forestales y Recursos Naturales, \\ Instituto de Bosques y Sociedad, Valdivia, Chile, tel.: 56-63-2293553. \\ ` Universidad Austral de Chile, Centro de Investigación en Suelos Volcánicos CISVo. \\ e Instituto Forestal (INFOR), Valdivia, Chile, tel.: 56-63-2335200. \\ ${ }^{\text {f }}$ Universidad de Concepción, Departamento de Suelos, Programa de Agricultura de Precisión, Chillán, Chile, \\ tel.: 56-42-2208881.
}

\begin{abstract}
SUMMARY
Forest biomass is one of the main alternatives that Chile could promote to supply the long-term demand of energy, which can help to diversify the national energy offer. In this study we assessed the biomass availability from native forests, considering biomass extraction based on silvicultural management and environmental and legal restrictions in three regions of south-central Chile: La Araucanía, Los Ríos and Los Lagos. Based on the proposed scenario, the potential area of forest biomass decreased from 1,330,460 to 754,435 ha and the estimated forest biomass reached $31 \mathrm{Gg}$. According to these results, the electric and calorific potential energy is $26 \mathrm{GWh}$ and $54 \mathrm{GWh}$, respectively. In a simulated scenario where the annual management represents $5 \%$ of the available biomass area $\left(37,000\right.$ ha year $\left.^{-1}\right)$, the energy would satisfy the demand of more than 700 thousand homes. The use of forest biomass for energy production has several advantages which produce economic, social and environmental positive impacts. A key strategy for the development of this activity is related to the incentive to manage the native forests, which are mainly property of small and medium land owners. Further research on this topic should explicitly consider issues as spatial and temporal scale, accessibility, biomass quality, and socio-economic conditions of land owners.
\end{abstract}

Key words: forest biomass, dendroenergy, non-conventional renewable energy, forest management, calorific value.

\section{RESUMEN}

El uso de biomasa forestal para la producción de energía eléctrica representa una de las alternativas que Chile podría utilizar para suplir la demanda de energía en el largo plazo, propiciando una mayor diversificación en la matriz energética. Este estudio cuantificó la disponibilidad de biomasa forestal de bosque nativo en las regiones de La Araucanía, Los Ríos y Los Lagos del centro-sur de Chile. Se consideró una extracción basada en intervenciones silviculturales, restricciones ambientales y legales, estimando la distribución espacial y el potencial energético de la biomasa. Al considerar las restricciones ambientales y legales, la superficie potencialmente manejable se redujo de 1.330 .460 a 754.435 hectáreas, y la biomasa potencial disponible se estimó en 31 Gg. El potencial de energía eléctrica y calórica equivale a $26 \mathrm{GWh}$ y $54 \mathrm{GWh}$, respectivamente. En un escenario simulado, con manejo anual de $5 \%$ de la superficie disponible (37.000 ha año-1), la energía podría cubrir las necesidades energéticas (eléctrica y térmica) de más de 700.000 hogares de consumo promedio. La utilización de biomasa para producir energía tiene varias ventajas que pueden generar impactos positivos (económicos, sociales y ambientales). Una estrategia clave para el desarrollo de la actividad está ligada al incentivo para el manejo del bosque nativo, que se encuentra mayormente en manos de pequeños y medianos propietarios. Futuras investigaciones en esta materia deberían considerar explícitamente aspectos de escala espacial y temporal, accesibilidad, calidad de biomasa y condiciones socioeconómicas de los propietarios.

Palabras clave: biomasa forestal, dendroenergía, energías renovables no convencionales, manejo forestal, poder calorífico. 


\section{INTRODUCCIÓN}

En Chile, durante los últimos 20 años, la demanda de energía se ha incrementado en forma sostenida, proyectándose para el año 2025 una tasa promedio de crecimiento anual de 5,5\%, alcanzando una demanda de $105.560 \mathrm{GWh}$ (Universidad de Chile y Universidad Técnica Federico Santa María 2008). El incremento en la demanda está siendo suplido principalmente por combustibles fósiles importados (petróleo crudo y gas natural), aumentando su consumo entre 1991 y 2010 en un 71,9 \% (Paneque et al. 2011). La necesidad de disminuir la dependencia de las importaciones de combustibles y de diversificar la matriz energética requiere buscar alternativas complementarias a este tipo de combustibles. Potenciar el uso de fuentes locales y renovables de energía, como la biomasa forestal, es fundamental para alcanzar el autoabastecimiento energético del país y disminuir la dependencia de fuentes externas (Reyes 2005), propiciando una mayor participación de las energías renovables no convencionales (ERNC) dentro de la matriz energética.

El uso de la biomasa forestal para la producción de energía representa una de las alternativas que Chile podría implementar para suplir la demanda de energía en el largo plazo. Anualmente se consumen 16 millones de metros cúbicos de leña, de los cuales más del $60 \%$ proviene del bosque nativo (INFOR 2012). Esta leña se utiliza principalmente a nivel residencial para calefacción, contribuyendo con el 17,6 \% de la energía generada en la matriz energética primaria (CNE 2011). Por otra parte, la generación eléctrica a partir de biomasa forestal es producida utilizando residuos o subproductos de la industria forestal, basada en plantaciones de especies exóticas, siendo su aporte de aproximadamente un $2 \%$ de la matriz energética nacional (CER 2014). Estas empresas inyectan el excedente de su producción eléctrica, luego de satisfacer sus necesidades energéticas. La ley 20.257/10 fija un porcentaje mínimo de participación de las ERNC en la matriz de generación eléctrica nacional, donde las empresas generadoras fueron obligadas a aumentar la participación de las ERNC hasta un $5 \%$ antes del año 2014, exigencia que después se incrementará a una tasa de $0,5 \%$ al año hasta alcanzar el $10 \%$ el año 2024. Todo lo anterior permite suponer que, si bien la biomasa forestal es un componente marginal de la matriz de generación eléctrica actual del país, existe la oportunidad para aumentar su participación dentro del país en un futuro cercano.

Una de las barreras que actualmente existen para el desarrollo de la industria dendroenergética nacional es la incertidumbre con respecto a la disponibilidad real de la biomasa forestal. La mayor disponibilidad de superficie forestal se encuentra en el bosque nativo. De acuerdo a la última actualización del catastro de bosque nativo, este representa aproximadamente el $80 \%$ de la superficie forestal del país (CONAF 2011). De acuerdo con INFOR (2012) el principal producto del bosque nativo ha sido la leña para cale- facción domiciliaria e industrial. Sin embargo, se señala que un alto porcentaje de la leña (aproximadamente $90 \%$ ) se extrae sin planes de manejo, lo que ha disminuido la calidad y capacidad productiva de muchos bosques nativos del centro sur de Chile (Lara et al. 2013). La extracción selectiva, causada por la alta demanda y mayor precio de leña de ciertas especies, ha favorecido procesos de degradación (Reyes 2005). Por ejemplo, en la provincia de Llanquihue, la tasa media de extracción de los productores de leña fue de $9,8 \mathrm{~m}^{3} \mathrm{ha}^{-1}$ año-1 (Reyes 2005), la cual es muy superior a los 5,6 $\mathrm{m}^{3} \mathrm{ha}^{-1}$ año-1 de productividad media estimada en estos bosques (INFOR 2011).

Las intervenciones silviculturales en distintos estados y condiciones de bosque nativo podrían generar gran cantidad de biomasa, donde una parte podría ser utilizada para fines bioenergéticos. Es el caso de los bosques no regulados, donde la proporción de madera aserrable alcanza a 20-30 \%, el restante volumen sólo es utilizable para astillas o leña (Reyes 2005). A medida que los bosques son intervenidos silviculturalmente, el porcentaje de madera de alta calidad aumenta, pudiendo invertirse esta relación, apoyando indirectamente la recuperación de potencial productivo de estos bosques (Donoso y Lara 1996). Esto es especialmente relevante, dado el impulso al manejo del bosque nativo que pudiera darse con la ley 20.283/08 sobre Recuperación del Bosque Nativo y Fomento Forestal.

En este contexto, dada las diferentes condiciones de sitios y estados de conservación de bosque nativo presentes en la región centro sur de Chile, se plantea como interrogante en este estudio si ¿es posible una utilización de biomasa con fines dendroenergéticos, de mediana a pequeña escala, bajo restricciones técnicas y ambientales, que aseguren la conservación del recurso bosque en largo plazo? Para ello se plantearon los siguientes objetivos: (a) estimar la disponibilidad de bosque nativo considerando un escenario de extracción sostenible de biomasa basado en las restricciones legales actuales, y (b) analizar la distribución espacial y el potencial energético (generación de energía eléctrica y calor) de la biomasa potencial disponible de los bosques nativos en el centro-sur de Chile. En este trabajo se planteó un escenario de manejo de producción sustentable, el cual considera porcentajes de extracción de acuerdo al tipo de bosque y variables restrictivas para extraer la biomasa, donde es posible satisfacer la demanda energética de localidades rurales del centro-sur de Chile debido a una mayor disponibilidad y accesibilidad a la biomasa forestal.

\section{MÉTODOS}

Área de estudio. El área de estudio incluye las regiones administrativas de La Araucanía, Los Ríos y la provincia de Osorno en la región de Los Lagos $\left(74^{\circ}-71^{\circ} \mathrm{O}\right.$ y $\left.37^{\circ}-41^{\circ} \mathrm{S}\right)$. La superficie total abarca 5.663.248 hectáreas y con una altitud desde el nivel del mar hasta $2.896 \mathrm{~m} \mathrm{snm}$. Esta área geográfica posee una gran proporción de bosques nativos (CONAF 2011), especialmente con características que des- 
tacan por sus tasas de crecimiento y accesibilidad (Echeverría y Lara 2004, Esse et al. 2013). Los tipos forestales, de acuerdo a Donoso (1994), presentes en el área de estudio son: roble-raulí-coigüe, coigüe-raulí-tepa, siempreverde, lenga, araucaria, alerce, ciprés de la cordillera y ciprés de Las Guaitecas, cada uno de los cuales está clasificado en sus correspondientes subtipos forestales. Para la estimación de la biomasa disponible se consideraron sólo los tipos forestales con mayor superficie y accesibilidad, así como posibilidad de intervenirlos silviculturalmente de acuerdo con la legislación actual (Echeverría y Lara 2004, Esse et al. 2013, Pilquinao 2013): roble-raulí-coigüe, coigüe, raulítepa y siempreverde, los cuales representan un $78 \%$ de la superficie total de bosque nativo del área de estudio.

La estimación de la biomasa de bosque nativo potencialmente disponible con fines energéticos, su distribución espacial y la cuantificación de su potencial energético se realizó en cinco etapas: (1) cuantificación de la superficie y distribución espacial, (2) asignación de subtipos forestales a la cobertura de bosque, (3) estimación de biomasa bruta por subtipo forestal, (4) estimación de la biomasa disponible con fines energéticos, (5) estimación del poder calorífico y potencial energético de la biomasa y (6) análisis de la accesibilidad.

Cuantificación de la superficie y distribución espacial. Para la delimitación de la cobertura de bosque nativo se realizó una clasificación supervisada de imágenes satelitales (Altamirano y Lara 2010), utilizándose un mosaico de imágenes (años 2008 y 2009) del sensor ASTER (Advanced Spaceborne Thermal Emission and Reflection Radiometer).

Las imágenes fueron clasificadas en siete categorías de coberturas: bosque nativo (vegetación con especies nativas $>2$ m de altura, $>25 \%$ de cobertura de copas, incluyendo bosques adultos y renovales), matorral (vegetación $<2$ m de altura, cobertura de árboles $<25 \%$, y cobertura de matorrales entre 10-25\%), plantación forestal (especies exóticas como Pinus radiata D. Don. y Eucalyptus spp.), terrenos agrícolas y praderas, suelo descubierto (playas, dunas, áreas rocosas, ciudades) y cuerpos de agua. A las imágenes clasificadas se les realizó un post-proceso para mejorar la exactitud de clasificación y minimizar los errores, denominado "clasificación experta" (Lu y Weng 2007). La exactitud global de la clasificación alcanzó un 93 \% de píxeles correctamente asignados.

Asignación de subtipos forestales a la cobertura de bosque nativo. La asignación se realizó a partir de la información contenida en las actualizaciones del catastro de bosque nativo (CONAF 2011), información que fue vinculada con la cobertura de bosque nativo generada a partir de la clasificación de imágenes satelitales. A cada píxel de bosque nativo se le asignó un subtipo forestal, mediante la intersección de la clasificación con el catastro de bosque nativo, obteniendo un mapa categórico de los subtipos forestales.
Estimación de biomasa total (biomasa arbórea aérea). Para estimar la biomasa contenida en los tipos forestales seleccionados se confeccionó una base de datos a partir de parcelas de inventario forestal de diferentes estudios preexistentes. Se realizaron nuevas parcelas de inventario forestal en zonas geográficas o tipos forestales, en áreas donde la información era incompleta. Los proyectos utilizados fueron: (a) inventario forestal de la región de Los Lagos, correspondiente al catastro de bosque nativo (CONAF 2011); (b) parcelas de inventario temporales de renovales de roble-raulí-coigüe de proyectos de la Universidad Austral de Chile (Lara et al. 1999, 2006); (c) parcelas de inventario temporales del proyecto FONDEF D97I1065 y (d) parcelas del proyecto FONDECYT 1110744. La base de datos dispuso de 321 parcelas geo-referenciadas (cuadro 1). Además, la base consideró otras 224 ubicadas a nivel de comuna, quedando un total de 545 parcelas.

En cada parcela se estimó la biomasa arbórea aérea, empleando funciones alométricas a nivel de especie (Milla et al. 2013) incluyendo los componentes no comerciales de los árboles (corteza, ramas, hojas). Para aquellas especies que no contaron con funciones de biomasa, se emplearon funciones de volumen locales (Corvalán 1987, Donoso 1988) que incluyen corteza y consideran un índice de utilización de $10 \mathrm{~cm}$. Luego, para estimar la biomasa, se multiplicó el volumen con corteza por la densidad básica promedio de la madera (Pérez 1983). Finalmente, para obtener la biomasa arbórea aérea, se multiplicó la biomasa por factores de expansión determinados por Gayoso et al. (2002). Para estimar la biomasa arbórea aérea se consideraron todos los árboles de la parcela con un diámetro a la altura del pecho (DAP) $\geq 5 \mathrm{~cm}$. Con la biomasa estimada por parcela, se obtuvo finalmente la biomasa total promedio de cada uno de los principales tipos y subtipos forestales (figura 1).

Para la estimación de la biomasa se calculó un error de estimación, el cual consideró un $95 \%$ de confianza. Provincias en las cuales no hubiera datos de parcela en alguno de sus tipos forestales, se consideraron los datos de parcelas del mismo subtipo presentes en otra provincia vecina, donde las condiciones de sitio fueran similares (combinación de clima y suelo). Se asignó el valor de biomasa más bajo registrado en el colectivo de las parcelas de ese subtipo.

Estimación de la biomasa potencial disponible con fines energéticos. La biomasa estimada con fines energéticos es aquella restante, luego de la aplicación de intervención silvícola, de acuerdo con restricciones ambientales y legales. Se utilizó un enfoque de cortas intermedias (raleos) y de regeneración, con extracción del 30-35 \% del área basal, dependiendo del bosque y según tipo forestal (DS 259 del DL 701). Del área basal extraída, se restó el equivalente de biomasa aserrable y pulpable de acuerdo a cifras de INFOR (2009) estimadas por provincia y tipo forestal (cuadro 2). De acuerdo con esta información, la biomasa ase- 
Cuadro 1. Descripción y características de las unidades muestrales utilizadas en la estimación de la biomasa de este estudio. Description and characteristics of inventory plots in this study.

\begin{tabular}{|c|c|c|c|}
\hline Fuente & Tipo forestal & Superficie parcela $\left(\mathrm{m}^{2}\right)$ & $\mathrm{N}$ \\
\hline \multirow{7}{*}{ CONAF et al. (1999) } & roble-raulí-coigüe & 100 & 18 \\
\hline & & 250 & 27 \\
\hline & & 500 & 26 \\
\hline & coigüe-raulí-tepa & 500 & 52 \\
\hline & siempreverde & 100 & 19 \\
\hline & & 250 & 25 \\
\hline & & 500 & 57 \\
\hline \multirow{2}{*}{ Proyecto Convenio UACh-LP (1999 y 2006) } & roble-raulí-coigüe & 250 & 50 \\
\hline & & 500 & 68 \\
\hline \multirow{5}{*}{ Proyecto FONDEF D97I1065. } & roble-raulí-coigüe & 125 & 44 \\
\hline & & 250 & 22 \\
\hline & & 500 & 70 \\
\hline & & 625 & 7 \\
\hline & & 1.000 & 1 \\
\hline Proyecto FONDECYT 1110744. & siempreverde & 900 & 9 \\
\hline \multirow{4}{*}{ Proyecto FONDEF D08I1056. } & roble-raulí-coigüe & 300 & 1 \\
\hline & coigüe-raulí-tepa & 500 & 11 \\
\hline & siempreverde & 300 & 26 \\
\hline & & 500 & 12 \\
\hline
\end{tabular}

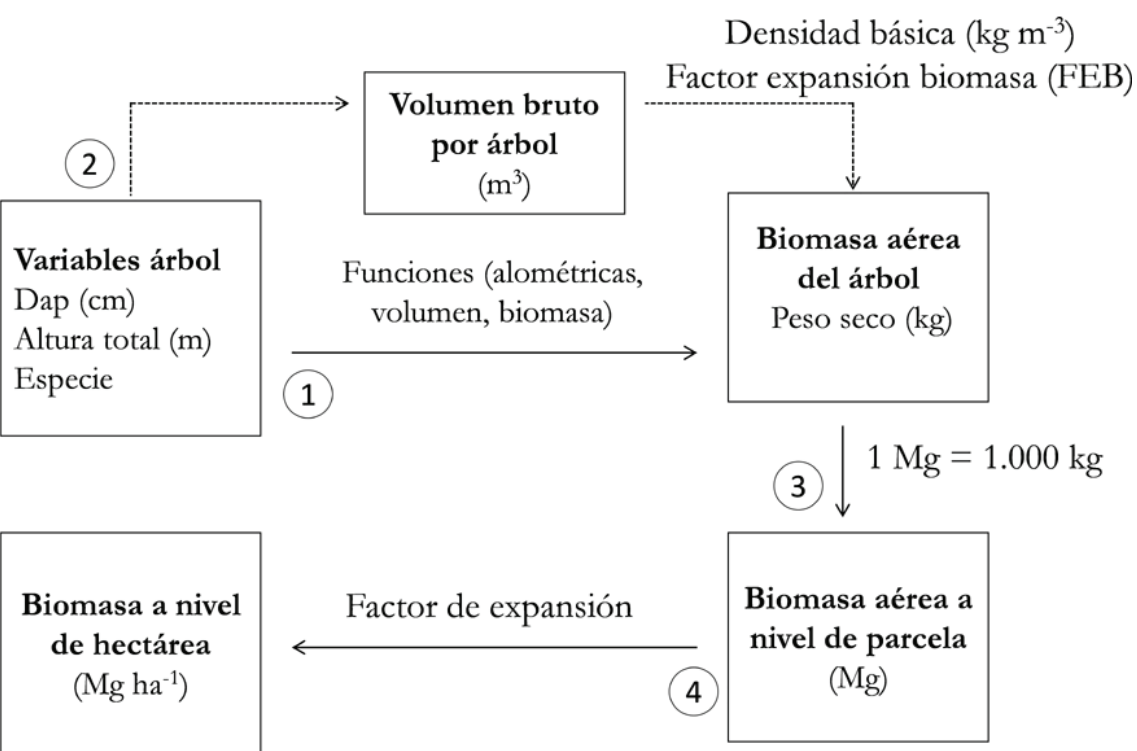

(1) Cálculo directo de la biomasa aérea del árbol utilizando una función alométrica.

(2) Cálculo indirecto de la biomasa aérea del árbol utilizando una función de volumen y valores de densidad básica.

(3) Secuencia de cálculo incluyendo factores de expansión a nivel de parcela y a nivel de superficie por tipo de bosque.

Figura 1. Diagrama de flujo que describe las variables utilizadas para la utilización de las funciones (alométricas, biomasa o volumen), y cómo, a partir de esta información, se obtuvo la biomasa aérea del árbol y cómo se expande a nivel de parcela y hectárea.

Chart describing the variables used for functions (allometric, biomass or volume), and how tree above-ground biomass, together with its expansion factor to plot and hectare level, is estimated with this information. 
rrable y pulpable variaría entre 55 y $70 \%$ en los distintos tipos forestales. Por lo tanto, de la biomasa que se extrae de acuerdo al escenario de manejo propuesto, lo restante posterior al uso forestal podría ser destinado a biomasa para producción de energía.

Se definieron siete variables espacialmente explícitas que representan las principales restricciones de tipo ambiental, que se encuentran en la legislación chilena (DL 701/1974 y Ley 18.362/84) respecto a las intervenciones en bosque nativo: (1) áreas silvestres protegidas por el Estado (SNASPE), (2) sitios prioritarios para la conservación de la biodiversidad, (3) áreas protegidas privadas, (4) restricciones de pendiente (mayores a $45 \%$ ), (5) tipos forestales protegidos (araucaria, alerce, ciprés de la cordillera y ciprés de Las Guaitecas), además del tipo forestal lenga, y los bosques riparios (25 m perpendiculares desde cada curso de agua). Las variables fueron definidas mediante la utilización de información geo-referenciada disponible para el área de estudio (CONAF 2014).

Estimación del poder calorifico y potencial energético de la biomasa forestal. El poder calorífico $\left(\mathrm{kcal} \mathrm{kg}^{-1}\right)$ se determinó a través de la extracción de tarugos de incremento y ramas. Las muestras se extrajeron de 22 parcelas, en cuatro o cinco especies arbóreas principales, donde en suma aportaban más del 80 \% del área basal de cada rodal. Se seleccionaron 10 individuos por cada especie con el fin de extraer un tarugo de incremento en cada una de ellas.

Se recolectaron entre 6 y 16 muestras de cada especie siguiendo la proporción descrita. Se separó el material de cada una de las especies, para luego triturar y mezclar el aserrín resultante, el cual debía mantener las proporciones originales. El material fue secado $\left(105 \pm 3^{\circ} \mathrm{C}\right)$ hasta obtener masa constante, y posteriormente se fabricó un pellet representativo de cada parcela muestreada. Los resultados de poder calorífico según la especie fueron llevados de kilocalorías por unidad de peso $\left(\mathrm{kcal} \mathrm{kg}^{-1}\right)$ a unidades de kilowatt hora por unidad de peso $(1 \mathrm{kcal}=0,001163 \mathrm{kwh})$ y luego a Megawatts hora por unidad de peso $(1 \mathrm{MWh}=$ 1,000 kwh). El poder calorífico contenido en una unidad de peso $(\mathrm{kg})$ fue ponderado por la biomasa total a nivel de hectárea $\left(\mathrm{Mg} \mathrm{ha}^{-1}\right)$, obteniendo como resultado final el potencial energético expresado en Megawatts hora a nivel de hectárea $\left(\mathrm{MWh} \mathrm{ha}^{-1}\right)$.

Para estandarizar estos resultados, se calculó el poder calorífico para dos niveles de humedad: $0 \%$ corresponde a la biomasa secada hasta obtener masa constante y $30 \%$ en base húmeda (b.h.). Esta operación se basó en la estimación del poder calorífico superior y del poder calorífico inferior (Meléndez y Torres 2007).

El potencial energético se calculó mediante la transformación del poder calorífico inferior a energía aprovechable mediante el uso de un coeficiente de eficiencia. Se consideró una eficiencia de conversión a energía eléctrica de $26,4 \%$, y a energía calórica de 53,6 \%, en tanto que la diferencia se corresponde a la pérdida de energía del sistema. El poder calorífico promedio a nivel de subtipo forestal se obtuvo ponderando el valor energético de cada especie por su porcentaje de participación en área basal para cada subtipo forestal considerado. Finalmente, el potencial energético total se determinó ponderando el potencial energético a nivel de hectárea por la superficie (hectáreas) de bosques ocupados por cada subtipo forestal. La biomasa disponible y potencial energético por provincia se analizó a un $30 \%$ de contenido de humedad y las variables determinadas fueron: poder calorífico superior (PET 30), potencial de energía eléctrica (PEE 30) y energía calórica (PEC 30).

Análisis de accesibilidad. Se calculó la proporción de biomasa y de energía potencial disponible en función de la altitud y la distancia a las principales vías de acceso (carreteras, caminos de asfalto y ripio), pueblos ( $<5.000$ habitantes) y ciudades (> 5.000 habitantes) (INE 2005). Para este análisis se consideró la energía potencial con un 30 \% de humedad de la biomasa forestal, ya que representa la condición más típica que utiliza la central que se usó como referencia.

\section{RESULTADOS}

Biomasa total y potencial disponible. La biomasa total fue estimada en 583.982.497 Mg. Los valores de biomasa total promedio variaron significativamente entre provincias y subtipos forestales. Las provincias con una mayor propoción de la biomasa total fueron Valdivia (26\%), Ranco (23 \%) y Osorno (23 \%). A nivel de tipos forestales el tipo coigüe-raulí-tepa presentó la mayor proporción, equivalente al $37 \%$ del total de la biomasa bruta, aunque también es el tipo que presenta la mayor variación (186 a $843 \mathrm{Mg} \mathrm{ha}^{-1}$ ). Estos extremos se presentaron en la misma provincia (Valdivia) y tipo forestal (siempreverde), y correspondieron a los subtipos renovales de coigüe de Chiloé y de canelo, respectivamente (cuadro 2).

La biomasa potencial disponible, luego de aplicar los tratamientos silviculturales (cortas intermedias y cortas de regeneración), considerando el aprovechamiento de productos aserrables y pulpables), fue equivalente a 63.901.565 Mg, aproximadamente un $10 \%$ de la biomasa total. La superficie de bosque nativo aprovechable, al considerar las restricciones legales, se redujo de 1.330 .460 a 754.435 hectáreas, y la biomasa potencial disponible fue estimada en 31.176.148 Mg (cuadro 2), equivalente al $5 \%$ de la biomasa total de la región. Las provincias de Cautín, Ranco y Valdivia concentraron la mayor cantidad de biomasa potencial disponible con fines energéticos, representando $25 \%$, $23 \%$ y $23 \%$ de la biomasa total, respectivamente. A nivel de tipos forestales, el tipo roble-raulícoigüe fue el de mayor importancia, concentrando el $45 \%$ de la biomasa potencialmente disponible (cuadro 2).

El error de estimación (EE) de la biomasa total promedio para todos los subtipos forestales en las diferentes provincias fue de $36 \%$. En general los mayores errores se 
Cuadro 2. Biomasa total y potencial disponible en función de proporción de extracción, aprovechamiento y restricciones ambientales y legales por provincia, tipo y subtipo forestal*.

Total and net biomass according to extraction, utilization and environmental and legal restrictions by province, forest type and forest subtype.

\begin{tabular}{|c|c|c|c|c|c|c|c|}
\hline Provincia & Tipo forestal & Subtipo forestal & $\begin{array}{c}\text { Total } \\
\left(\mathrm{Mg} \mathrm{ha}^{-1}\right)\end{array}$ & $\begin{array}{c}\text { Potencial } \\
\text { disponible } \\
\left(\mathrm{Mg} \mathrm{ha}^{-1}\right)^{\mathrm{a}}\end{array}$ & $\begin{array}{c}\text { Superficie } \\
\text { total (ha) }\end{array}$ & $\begin{array}{l}\text { Superficie } \\
\text { neta (ha) }\end{array}$ & $\begin{array}{l}\text { Total potencial } \\
\text { disponible final } \\
(\mathrm{Mg})^{\mathrm{c}}\end{array}$ \\
\hline \multirow[t]{8}{*}{ Malleco } & roble-raulí-coigüe & renoval roble-raulí-coigüe & 340 & 31 & 65.392 & 48.553 & 1.484 .960 \\
\hline & & renoval coigüe & 486 & 44 & 8.762 & 7.794 & 341.057 \\
\hline & & renoval roble & 250 & 23 & 78.771 & 66.707 & 1.503 .026 \\
\hline & coigüe-raulí-tepa & coigüe-raulí-tepa & 307 & 37 & 15.508 & 6.248 & 229.934 \\
\hline & & bosque coigüe & 297 & 36 & 2.235 & 1.939 & 69.177 \\
\hline & & coigüe-tepa & 215 & 26 & 527 & 134 & 3.452 \\
\hline & siempreverde & siempreverde & 254 & 28 & 464 & 358 & 10.169 \\
\hline & & mirtáceas & 223 & 25 & 288 & 240 & 6.002 \\
\hline \multirow[t]{9}{*}{ Cautín } & roble-raulí-coigüe & renoval roble-raulí-coigüe & 506 & 46 & 34.822 & 24.100 & 1.098 .468 \\
\hline & & renoval coigüe & 387 & 35 & 70.654 & 43.563 & 1.516 .620 \\
\hline & & renoval roble & 243 & 22 & 138.989 & 116.005 & 2.536 .642 \\
\hline & coigüe-raulí-tepa & coigüe-raulí-tepa & 423 & 51 & 9.180 & 7.040 & 357.378 \\
\hline & & bosque coigüe & 297 & 36 & 38.204 & 20.549 & 732.947 \\
\hline & & coigüe-tepa & 371 & 44 & 24.267 & 13.755 & 611.683 \\
\hline & siempreverde & siempreverde & 189 & 21 & 845 & 787 & 16.650 \\
\hline & & mirtáceas & 409 & 46 & 21.843 & 20.825 & 953.635 \\
\hline & & bosque coigüe & 223 & 25 & 6.846 & 5.925 & 147.914 \\
\hline \multirow[t]{10}{*}{ Valdivia } & roble-raulí-coigüe & renoval roble-raulí-coigüe & 308 & 32 & 4.235 & 442 & 14.312 \\
\hline & & renoval coigüe & 394 & 41 & 22.943 & 12.489 & 516.129 \\
\hline & & renoval roble & 312 & 33 & 57.165 & 39.088 & 1.281 .737 \\
\hline & coigüe-raulí-tepa & coigüe-raulí-tepa & 702 & 91 & 43.208 & 8.819 & 798.242 \\
\hline & & bosque coigüe & 667 & 86 & 42.248 & 15.800 & 1.358 .780 \\
\hline & & coigüe-tepa & 673 & 87 & 21.312 & 9.936 & 862.787 \\
\hline & siempreverde & renoval canelo & 186 & 17 & 14.067 & 8.500 & 143.480 \\
\hline & & coigüe de Chiloé & 843 & 77 & 13.655 & 2.153 & 165.180 \\
\hline & & siempreverde & 495 & 45 & 65.068 & 40.357 & 1.816 .378 \\
\hline & & mirtáceas & 264 & 24 & 5.016 & 1.495 & 35.870 \\
\hline \multirow[t]{10}{*}{ Ranco } & roble-raulí-coigüe & renoval roble-raulí-coigüe & 346 & 36 & 3.776 & 1.020 & 37.037 \\
\hline & & renoval coigüe & 487 & 51 & 19.920 & 14.298 & 731.357 \\
\hline & & renoval roble & 255 & 27 & 37.780 & 24.930 & 667.443 \\
\hline & coigüe-raulí-tepa & coigüe-raulí-tepa & 768 & 99 & 20.573 & 4.428 & 438.528 \\
\hline & & bosque coigüe & 519 & 67 & 32.854 & 17.322 & 1.159 .843 \\
\hline & & coigüe-tepa & 650 & 84 & 65.567 & 34.853 & 2.923 .470 \\
\hline & siempreverde & renoval canelo & 105 & 10 & 7.360 & 4.578 & 43.852 \\
\hline & & coigüe de Chiloé & 443 & 40 & 20.339 & 437 & 17.651 \\
\hline & & siempreverde & 564 & 51 & 51.633 & 19.834 & 1.018 .708 \\
\hline & & mirtáceas & 223 & 20 & 3.275 & 2.729 & 55.351 \\
\hline
\end{tabular}


Continuación Cuadro 2

\begin{tabular}{|c|c|c|c|c|c|c|c|}
\hline \multirow[t]{9}{*}{ Osorno } & roble-raulí-coigüe & renoval coigüe & 358 & 39 & 24.554 & 16.287 & 630.581 \\
\hline & & renoval roble & 280 & 30 & 27.053 & 23.468 & 708.775 \\
\hline & coigüe-raulí-tepa & coigüe-raulí-tepa & 307 & 31 & 20 & 0 & 0 \\
\hline & & bosque coigüe & 705 & 72 & 32.826 & 12.107 & 870.245 \\
\hline & & coigüe-tepa & 664 & 68 & 23.020 & 6.061 & 410.740 \\
\hline & siempreverde & renoval canelo & 272 & 34 & 11.494 & 5.641 & 193.488 \\
\hline & & coigüe de Chiloé & 651 & 82 & 55.093 & 7.492 & 614.518 \\
\hline & & siempreverde & 472 & 59 & 83.930 & 33.432 & 1.988 .184 \\
\hline & & mirtáceas & 223 & 28 & 2.878 & 1.915 & 53.767 \\
\hline Total & & & & & 1.330 .460 & 754.435 & 31.176 .148 \\
\hline
\end{tabular}

* Las cifras de biomasa y superficies fueron estimadas usando decimales, sin embargo éstos no fueron incorporados en el cuadro por razones de espacio.

${ }^{a}$ Biomasa ( $\mathrm{Mg} \mathrm{ha}^{-1}$ ) potencial disponible por subtipo forestal luego de aplicar cortas intermedias y de regeneración según tipo de bosque (Normas de manejo de CONAF), y descontando proporción de productos aserrables y pulpables (INFOR 2009).

${ }^{\text {b }}$ Superficie (hectáreas) equivalente a la diferencia entre la superficie total y las restricciones legales.

${ }^{c}$ Equivale a la biomasa potencial disponible por cada subtipo forestal $\left(\mathrm{Mg} \mathrm{ha}^{-1}\right)$ multiplicada por la superficie neta (hectáreas) de cada subtipo forestal.

observaron en aquellos subtipos forestales en los cuales se contó con un número bajo de parcelas, como fue el caso de la provincia de Ranco, específicamente en los subtipos renoval de roble-raulí-coigüe y renoval de coigüe, donde el número de parcelas registradas fue solo de tres y dos unidades, respectivamente. Una situación inversa se evidenció en aquellos subtipos con una cantidad mayor de unidades muestrales (cuadro 3).

La biomasa total mostró una clara concentración en áreas de la Cordillera de la Costa y de Los Andes, y en parches aislados en la Depresión Intermedia, y fundamentalmente en la región de Los Ríos (figura 2A). La biomasa potencial disponible disminuye de 843 a $99 \mathrm{Mg} \mathrm{ha}^{-1}$ considerando todas las restricciones impuestas, donde el patrón de distribución espacial mantuvo la misma tendencia que la biomasa total. Las áreas más restringidas en oferta de biomasa forestal fueron en la Cordillera de la Costa, principalmente en la región de Los Ríos y la provincia de Osorno (figura 2B), mientras que en la zona de Los Andes, el área con mayor disminución se observó en la zona norte de la región de Los Ríos.

Potencial energético. El poder calorífico superior (PCS) y poder calorífico inferior (PCI) (0\% y $30 \%$ de humedad) de la biomasa no mostraron mayores diferencias entre y dentro de los distintos tipos forestales considerados. El valor máximo de PCS se observó en el subtipo renoval de canelo (4.679 kcal kg-1) y el mínimo en coigüe de Chiloé (4.420 kcal kg-1) (cuadro 4). El poder calorífico medido a $30 \%$ de humedad disminuyó de manera importante con respecto al poder calorífico superior, disminución superior al 30 \% para cada tipo forestal. La distribución espacial de la biomasa determinó la distribución del potencial energético para la región estudiada (figura 3 ).
El potencial de generación de energía (electricidad y calor) para toda el área de estudio fue estimado en 101.036.323 MWh considerando $30 \%$ de humedad de la biomasa (cuadro 5). Bajo este escenario, y utilizando un valor de eficiencia eléctrica de $26 \%$ y térmica de $54 \%$, para una planta tipo de ciclo de vapor de $7 \mathrm{MW}$, el potencial de energía eléctrica fue equivalente a 26.693.800 MWh y de energía calórica a 54.155.451 MWh. En el mismo escenario, la región de Los Ríos concentró aproximadamente el $48 \%$ del potencial de generación de energía. A nivel provincial, el 70 \% del potencial de generación de energía se concentró en las provincias de Curacautín, Valdivia y Ranco (cuadro 5). El área de estudio incluyó un total de 51 comunas, donde 10 de ellas poseen aproximadamente el 54 \% del potencial de generación de la energía total del área de estudio. En orden decreciente, las diez comunas con mayor potencial de generación de energía fueron: La Unión, Panguipulli, Futrono, Máfil, Puerto Octay, Paillaco, Purranque, Cunco, Curacautín y Los Lagos.

La distribución espacial de la biomasa disponible y su potencial energético mostraron el mismo comportamiento, por lo tanto, la accesibilidad a la biomasa se relacionó directamente con el potencial energético. Se observó que al aumentar la altitud, disminuyó la accesibilidad (biomasa disponible y potencial energético); de este modo, cerca del $40 \%$ de la energía disponible se encontró a menos de $500 \mathrm{~m}$ snm, y cerca del $85 \%$ a menos de $1.000 \mathrm{~m}$ snm (figura 4A), es decir, la mayor parte de la energía se encuentra potencialmente disponible a menor elevación donde existió algún tipo de camino (figura 4B). Por ejemplo, poco más del 85 \% de la energía se encontró a una distancia inferior a 5 km, más del $95 \%$ a una distancia menor a $10 \mathrm{~km}$, y el total de la energía disponible se encontró a una distancia menor a $22 \mathrm{~km}$ de algún tipo de camino. 
Cuadro 3. Valores medios, máximos y mínimos de la biomasa total y error de estimación (\%) para los distintos tipos y subtipos forestales. $\mathrm{N}=$ número de parcelas.

\begin{tabular}{|c|c|c|c|c|c|c|c|}
\hline \multirow{2}{*}{ Provincia } & \multirow{2}{*}{ Tipo forestal } & \multirow{2}{*}{ Subtipo forestal } & \multicolumn{3}{|c|}{ Biomasa arbórea (Mg ha-1) } & \multirow{2}{*}{$\mathrm{N}$} & \multirow{2}{*}{ Error $(\%$} \\
\hline & & & Media & Máximo & Mínimo & & \\
\hline \multirow[t]{8}{*}{ Malleco } & roble-raulí-coigüe & renoval roble-raulí-coigüe & 340 & 869 & 46 & 22 & 25,38 \\
\hline & & renoval coigüe & 486 & 1.057 & 136 & 15 & 27,67 \\
\hline & & renoval roble & 250 & 537 & 36 & 16 & 29,74 \\
\hline & coigüe-raulí-tepa & coigüe-raulí-tepa & 307 & 307 & 307 & $* 1$ & - \\
\hline & & bosque coigüe & 297 & 297 & 297 & $* 1$ & - \\
\hline & & coigüe-tepa & 215 & 215 & 215 & $* 1$ & - \\
\hline & siempreverde & siempreverde & 254 & 254 & 254 & $* 1$ & - \\
\hline & & mirtáceas & 223 & 223 & 223 & $* 1$ & - \\
\hline \multirow[t]{9}{*}{ Cautín } & roble-raulí-coigüe & renoval roble-raulí-coigüe & 506 & 1.084 & 155 & 27 & 21,46 \\
\hline & & renoval coigüe & 387 & 1.046 & 41 & 24 & 24,84 \\
\hline & & renoval roble & 243 & 555 & 67 & 39 & 15,12 \\
\hline & coigüe-raulí-tepa & coigüe-raulí-tepa & 423 & 525 & 307 & 3 & 31,79 \\
\hline & & bosque coigüe & 297 & 297 & 297 & $* 1$ & - \\
\hline & & coigüe-tepa & 371 & 371 & 371 & $* 1$ & - \\
\hline & siempreverde & siempreverde & 189 & 189 & 189 & $* 1$ & - \\
\hline & & mirtáceas & 409 & 607 & 254 & 5 & 34,22 \\
\hline & & bosque coigüe & 223 & 223 & 223 & $* 1$ & - \\
\hline \multirow[t]{10}{*}{ Valdivia } & roble-raulí-coigüe & renoval roble-raulí-coigüe & 308 & 858 & 40 & 24 & 28,42 \\
\hline & & renoval coigüe & 394 & 793 & 102 & 31 & 16,71 \\
\hline & & renoval roble & 312 & 776 & 2 & 75 & 12,12 \\
\hline & coigüe-raulí-tepa & coigüe-raulí-tepa & 702 & 915 & 408 & 6 & 25,20 \\
\hline & & bosque coigüe & 667 & 667 & 667 & $* 1$ & - \\
\hline & & coigüe-tepa & 673 & 1.387 & 215 & 17 & 24,39 \\
\hline & siempreverde & renoval canelo & 186 & 394 & 3 & 8 & 63,94 \\
\hline & & coigüe de Chiloé & 843 & 965 & 721 & 2 & 30,62 \\
\hline & & siempreverde & 495 & 1.243 & 12 & 34 & 24,20 \\
\hline & & mirtáceas & 264 & 330 & 223 & 9 & 8,62 \\
\hline \multirow[t]{10}{*}{ Ranco } & roble-raulí-coigüe & renoval roble-raulí-coigüe & 346 & 567 & 28 & 3 & 99,83 \\
\hline & & renoval coigüe & 487 & 738 & 174 & 11 & 27,03 \\
\hline & & renoval roble & 255 & 792 & 42 & 14 & 43,16 \\
\hline & coigüe-raulí-tepa & coigüe-raulí-tepa & 768 & 923 & 479 & 4 & 27,75 \\
\hline & & bosque coigüe & 519 & 741 & 297 & 2 & 90,60 \\
\hline & & coigüe-tepa & 650 & 1.241 & 266 & 19 & 20,98 \\
\hline & siempreverde & renoval canelo & 105 & 283 & 35 & 6 & 79,20 \\
\hline & & coigüe de Chiloé & 443 & 765 & 270 & 4 & 52,49 \\
\hline & & siempreverde & 564 & 1.406 & 129 & 20 & 27,89 \\
\hline & & mirtáceas & 223 & 223 & 223 & $* 1$ & - \\
\hline
\end{tabular}

Mean, maximum and minimum of biomass and estimation error. Máximo = maximum, Mínimo = minimum, D.E.= standard deviation, $\mathrm{n}=$ number of plots. 


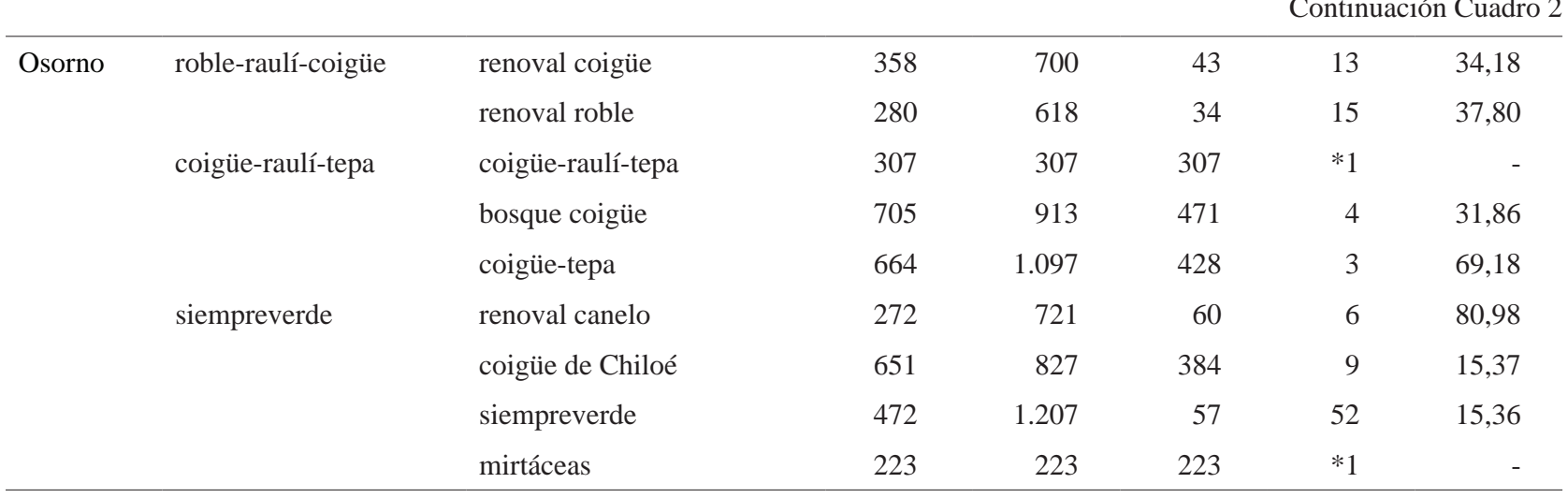

* En estos subtipos no se registraron datos de parcelas, por lo tanto, los valores de biomasa que se incluyeron corresponden a datos de parcelas del mismo subtipo presente en otra provincia. Para ello se consideró el valor de biomasa más bajo registrado en una parcela $(\mathrm{N}=1)$ perteneciente al mismo subtipo forestal.
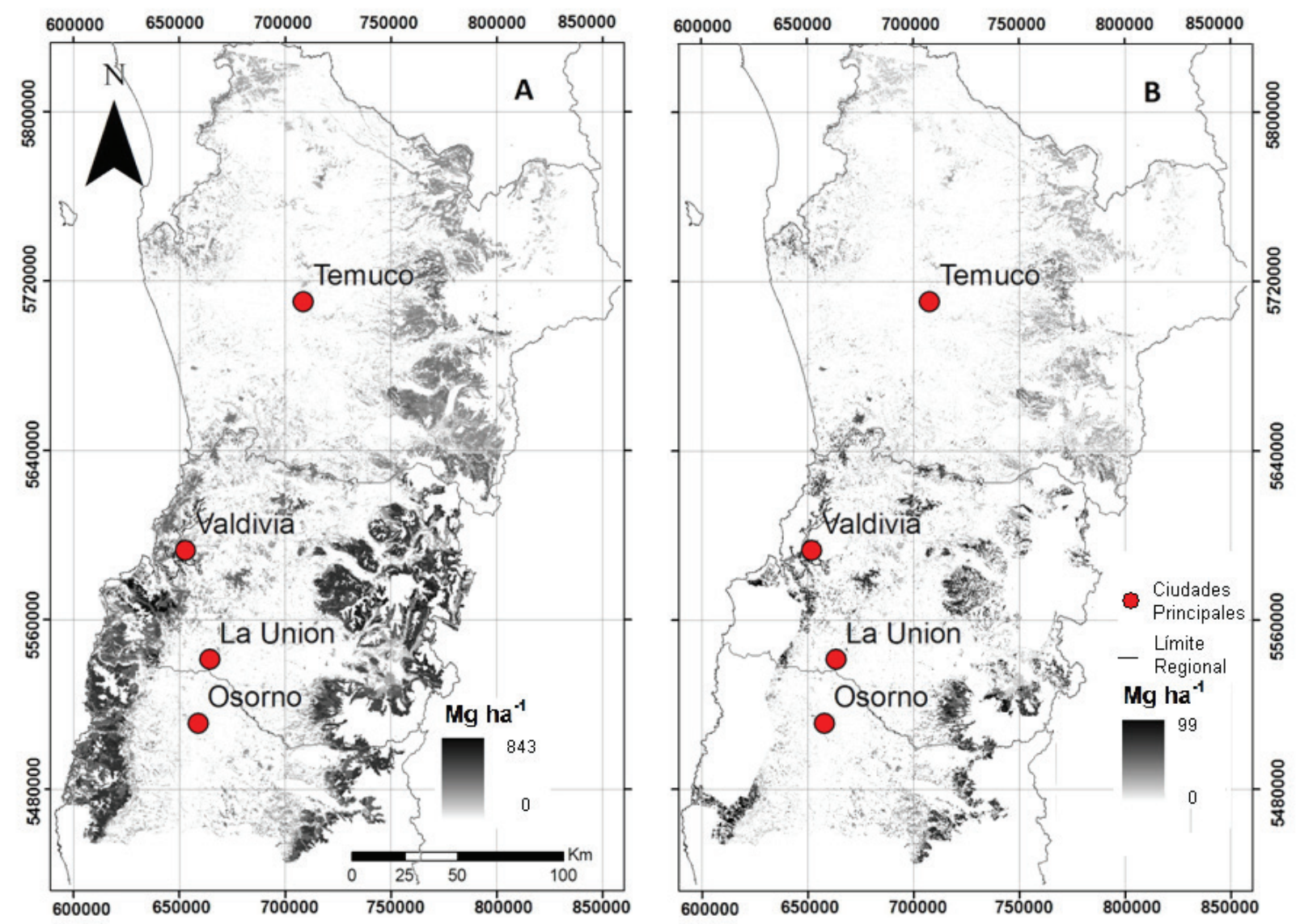

Figura 2. Mapa de la distribución espacial de la biomasa forestal ( $\left.\mathrm{Mg} \mathrm{ha}^{-1}\right)$ en el área de estudio: A) total y B) potencial disponible.

Map of the spatial distribution of forest biomass $\left(\mathrm{Mg} \mathrm{ha}^{-1}\right)$ in the study area: A) total, and B) net available.

Con respecto a los pueblos ( $<5.000$ habitantes), el $30 \%$ de la energía potencial se encontró a una distancia inferior a $10 \mathrm{~km}, 70 \%$ a menos de $20 \mathrm{~km}$, y el $80 \%$ a menos de $25 \mathrm{~km}$ (figura 4C). Las ciudades (>5.000 habitantes) en general, se encontraron más alejadas de los bosques, por ello, la ac- cesibilidad es un poco más restringida a la biomasa forestal. Sin embargo, el análisis mostró que aproximadamente $20 \%$ de la energía potencial se encontró a menos de $20 \mathrm{~km}$, $50 \%$ a menos de $35 \mathrm{~km}$ y $75 \%$ a menos de $50 \mathrm{~km}$ de alguna ciudad (figura 4D). 
Cuadro 4. Poder calorífico $\left(\mathrm{kcal} \mathrm{kg}^{-1}\right)$ superior (PCS) e inferior con $0 \%$ (PCI 0) y $30 \%$ de humedad (PCI 30), para los distintos tipos y subtipos forestales. D.E. = desviación estándar, $\mathrm{CV}=$ coeficiente de variación (\%).

Higher (PCS) and lower calorific value with $0 \%$ (PCI0) and $30 \%$ (PCI30) of water content, by forest type and forest sub-type. D.E.= standard deviation, $\mathrm{CV}=$ coefficient of variation $(\%)$.

\begin{tabular}{lllccrrrr}
\hline Tipo forestal & Subtipo forestal & PCS & Mínimo & Máximo & D.E. & CV & PCI 0 & PCI 30 \\
\hline roble-raulí-coigüe & renoval mixto & 4.586 & 4.461 & 4.623 & 72,5 & 1,6 & 4.264 & 2.810 \\
& renoval coigüe & 4.486 & 4.461 & 4.716 & 110,4 & 2,4 & 4.164 & 2.740 \\
& renoval roble & 4.591 & 4.514 & 4.623 & 55,2 & 1,2 & 4.269 & 2.813 \\
\hline coigüe-raulí-tepa & mixto & 4.514 & 4.461 & 4.597 & 64,8 & 1,4 & 4.192 & 2.759 \\
& bosque coigüe & 4.481 & 4.351 & 4.777 & 181,1 & 4,0 & 4.159 & 2.736 \\
& coigüe-tepa & 4.599 & 4.461 & 4.777 & 138,3 & 3,0 & 4.277 & 2.819 \\
\hline Siempreverde & renoval canelo & 4.679 & 4.580 & 4.755 & 89,7 & 1,9 & 4.357 & 2.874 \\
& coigüe de Chiloé ${ }^{1}$ & 4.420 & - & - & - & - & 4.098 & 2.693 \\
& siempreverde & 4.572 & 4.501 & 4.777 & 127,1 & 2,8 & 4.250 & 2.800 \\
& mirtáceas & 4.576 & 4.514 & 4.611 & 41,5 & 0,9 & 4.254 & 2.802 \\
\hline
\end{tabular}

${ }^{1}$ Para la especie coigüe de Chiloé sólo se realizó un análisis a nivel de mezcla de especies, por ello, no hay variaciones de poder calorífico.
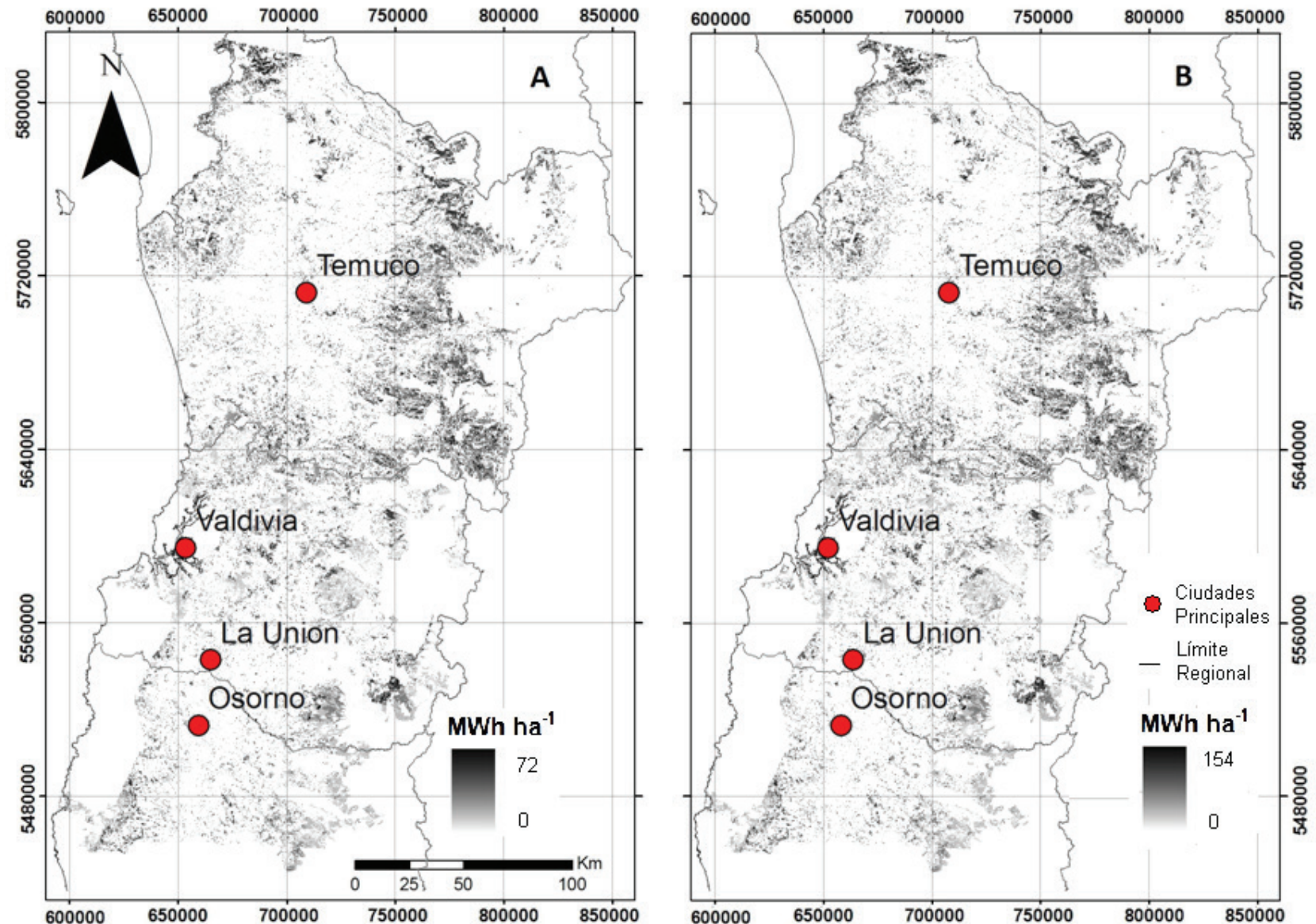

Figura 3. Mapa del potencial energético (MWh ha-1) de la biomasa en el área de estudio considerando 30 \% de humedad: A) electricidad, y B) calor.

Map of potential energy (MWh ha-1) of biomass in the study area considering $30 \%$ of water content: A) electricity, and B) heat. 
Cuadro 5. Biomasa potencial disponible y potencial energético por provincia considerando el poder calorífico superior (PET 30), el potencial de energía eléctrica (PEE 30) y energía calórica (PEC 30).

Available biomass and energy potential by province according to its higher calorific value (PET 30), electric energy potential (PEE 30) and calorific energy (PEC 30) with $30 \%$ of biomass water content.

\begin{tabular}{ccccc}
\hline Provincia & $\begin{array}{c}\text { Biomasa disponible } \\
(\mathrm{Mg})\end{array}$ & $\begin{array}{c}\text { PET30 } \\
(\mathrm{MWh})\end{array}$ & $\begin{array}{c}\text { PEE30 } \\
(\mathrm{MWh})\end{array}$ & $\begin{array}{c}\text { PEC30 } \\
(\mathrm{MWh})\end{array}$ \\
\hline Malleco & 3.624 .526 & 11.803 .491 & 3.118 .480 & 6.326 .663 \\
Cautín & 7.840 .798 & 25.423 .224 & 6.716 .812 & 13.626 .853 \\
Valdivia & 7.073 .081 & 22.948 .084 & 6.062 .886 & 12.300 .173 \\
Ranco & 7.135 .020 & 23.091 .252 & 6.100 .720 & 12.376 .900 \\
Osorno & 5.502 .724 & 17.770 .272 & 4.694 .903 & 9.524 .862 \\
Total & 31.176 .149 & 101.036 .323 & 26.693 .800 & 54.155 .451 \\
\hline
\end{tabular}
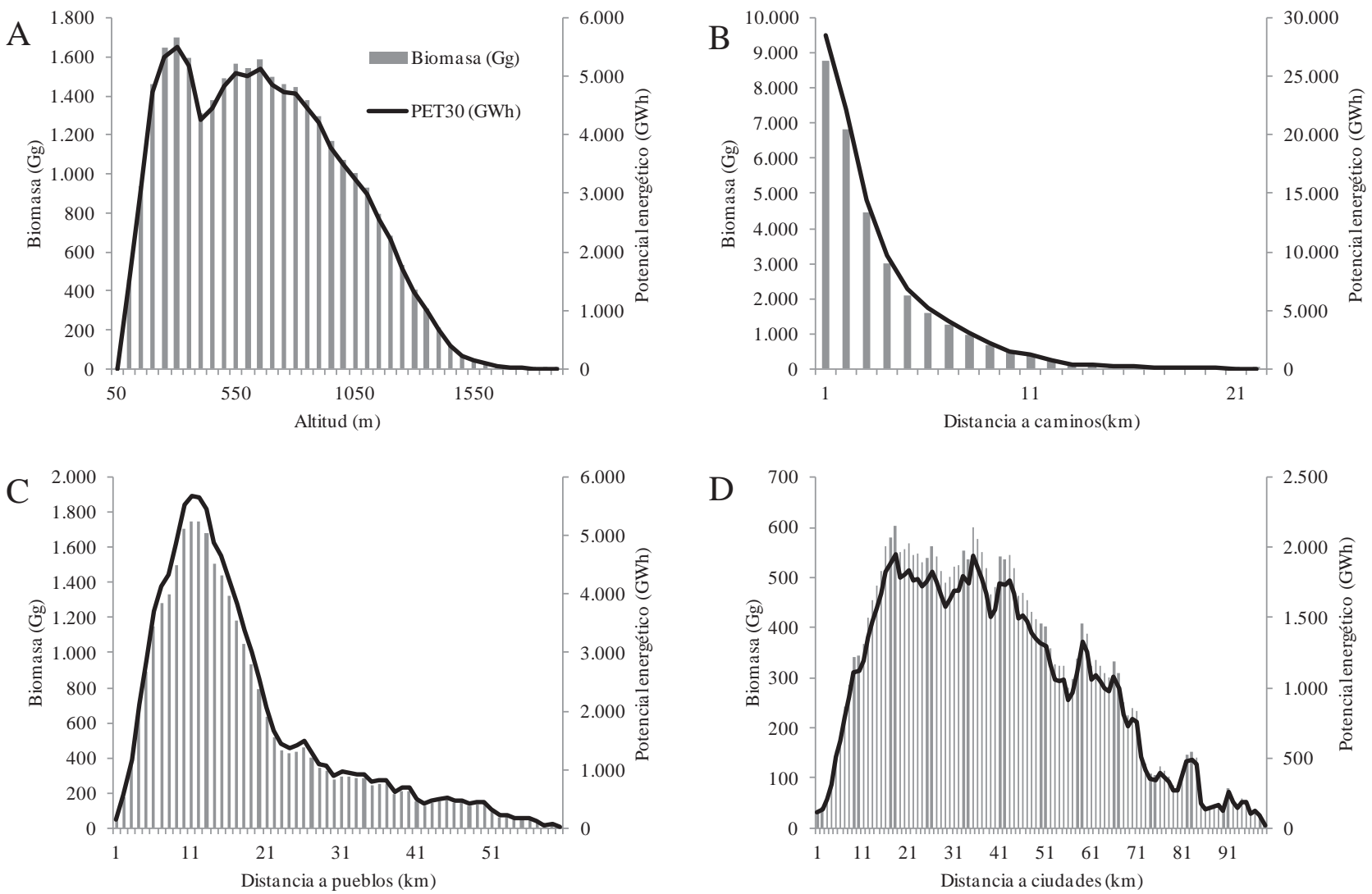

Figura 4. Disponibilidad de la biomasa y potencial energético (PET 30) considerando el poder calorífico inferior (PCI 30) de la biomasa en función de: (A) altitud, (B) distancia a caminos, (C) distancia a pueblos, y (D) distancia a ciudades.

Available biomass and energy potential (PET 30) considering lower calorific value and $30 \%$ of biomass water content according to: A) altitude, B) distance to roads, C) distance to towns and D) distance to cities. 


\section{DISCUSIÓN}

El enfoque metodológico, tanto por el tipo de información como en su tratamiento analítico, aparece como apropiado, pues genera resultados con potencial aplicación técnica y práctica dentro de los parámetros estimados por otros estudios con objetivos similares (Torres-Álvarez y Peña-Cortés 2011, CONAF 2014). De este modo, y ante la pregunta de los montos de biomasa disponible así como su potencial utilización con fines energéticos, esta puede ser respondida para un área definida y el recurso bosque asociado con ciertos niveles de precisión y exactitud. Sin embargo, lo anterior no está exento de problemas, debido principalmente a la diversidad de orígenes de los datos, los distintos objetivos para su captura y su disponibilidad o acceso. Todo esto genera dificultades y restricciones para realizar estimaciones, lo cual es propio de este tipo de estudios.

Por otro lado, y en lo específico a la estimación de biomasa referida a la definición de tipos y subtipos forestales actualmente en uso en Chile (Donoso 1981), favorece la aplicación y asociación casi inmediata, por parte de los actores forestales, a las condiciones de bosque presentes en el área de estudio. Así la utilización de esta información generada, dentro de las normas y criterios de manejo silvicultural contenidas en los diferentes cuerpos legales, facilitará el manejo forestal por un lado, pero también el control de las faenas ejecutadas, por parte de CONAF u otro organismo certificador.

Las estimaciones de biomasa con fines dendroenergético utilizadas, consideraron explícitamente el actual y principal producto derivado de las intervenciones silviculturales en bosque nativo, la leña para consumo residencial e industrial (Reyes 2005). Es decir, incluso considerando solo la extracción de una parte de la biomasa con fines dendroenergéticos hacia plantas de co-generación, este estudio estima que es posible destinar productos hacia ese uso. De este modo la cantidad de biomasa neta disponible mostró una relación casi directa con el estado actual del bosque. Del mismo modo, dado la poca variación de los poderes caloríficos, existe una relación también directa con las estimaciones de biomasa, es decir, a mayor biomasa disponible, mayor poder calorífico. Por lo tanto, una apropiada consideración del estado del bosque así como su potencial utilización, a través de cortas silviculturales, permitirán la obtención de biomasa y, por ende, poder generador con fines dendroenergéticos dentro de un enfoque sostenible en el largo plazo.

Las estimaciones de biomasa disponible para fines bioenergéticos corresponden a alrededor de un $10 \%$ de la biomasa potencial existente en el área de estudio. Estas cifras están muy por debajo de las estimaciones de biomasa forestal residual reportadas por Torres-Álvarez y Peña-Cortés (2011) para la cuenca del lago Ranco para los mismos tipos forestales aquí considerados. Incluso, la biomasa residual estimada para el tipo forestal siempreverde (484 $\mathrm{Mg} \mathrm{ha}^{-1}$ ) es superior a la biomasa potencial estimada en este estudio $\left(355 \mathrm{Mg} \mathrm{ha}^{-1}\right)$. Esto puede deberse a que Torres-Álvarez y Peña-Cortés (2011) sólo consideraron bosques adultos y tan solo un sitio de muestreo para cada tipo forestal, donde los sitios fueron seleccionados en áreas de cosecha reciente y los bosques presentan rendimientos de biomasa muy superior al promedio. INFOR (2009) presenta estimaciones promedio de 176, 200 y $301 \mathrm{Mg} \mathrm{ha}^{-1}$ para los tipos forestales siempreverde, roble-raulí-coigüe y coigüe-raulí-tepa, respectivamente, lo cual está por debajo de las estimaciones realizadas por este estudio. Una razón de esta diferencia podría deberse a que INFOR (2009) sólo considera la biomasa del fuste sin corteza, excluyendo la biomasa de la corteza, ramas, ramillas y hojas. El manejo del bosque nativo en toda el área de estudio, considerando los tipos forestales siempreverde, roble-raulí-coigüe y coigüe-raulí-tepa tendría un potencial para generar 3.047 MW brutos de energía, lo que es equivalente a 26.693.800 MWh, considerando potencial de energía eléctrica, biomasa con $30 \%$ de humedad y la eficiencia de una planta de $7 \mathrm{MW}$. Este potencial de 3.047 MW es superior a los 1.528 MW estimados por Pontt (2008) para la región de La Araucanía y Los Lagos, sin embargo, en el presente estudio se considera una utilización de sólo un 20 \% de la biomasa disponible del bosque nativo.

Según cifras de la encuesta CASEN (2006), una vivienda rural consume $125 \mathrm{kWh} \mathrm{mes}^{-1}$, en tanto que una vivienda urbana consume $159 \mathrm{kWh} \mathrm{mes}^{-1}$ de energía eléctrica. Basados en estas cifras, si se manejara anualmente el $5 \%$ de la superficie disponible (aproximadamente 37.000 ha año ${ }^{-1}$ ), la energía eléctrica potencialmente disponible sería de 1.334.690 MWh, lo cual cubriría las necesidades de aproximadamente 700 mil hogares urbanos o 800 mil hogares rurales, esto sólo considerando la biomasa disponible para fines bioenergéticos. En el mismo escenario, el calor que potencialmente se podría generar es de 2.707.773 MWh, pudiendo cubrir las necesidades de más de 900 mil hogares, si estos tuviesen un consumo mensual de $350 \mathrm{KWh}$ por ocho meses al año. En términos de generación eléctrica, el potencial de la biomasa es importante si se compara con otras fuentes de energía, como por ejemplo la central hidroeléctrica Rapel que produce en promedio 541,7 GWh al año (ENDESA 2012). La generación de energía de centrales basadas en energías alternativas, tales como "Canela II" (eólica) produjeron el año 2007 140,5 GWh, o "Los Molles" (hidroeléctrica de pasada) 59,2 GWh.

La región de estudio muestra un alto potencial para el desarrollo de proyectos energéticos basados en biomasa forestal, debido a la alta cantidad de biomasa de bosque nativo existente, así como la accesibilidad a dicha biomasa, aspecto que no es limitante debido a su relativa cercanía a caminos y lugares poblados que presentan potencial demanda de energía. En particular, hay localidades rurales como Panguipulli, Futrono, Cunco y Curacautín que presentan un alto potencial para satisfacer su demanda energética a partir de biomasa forestal. De la misma manera, se observa una ventaja comparativa en proyectos para 
abastecer de energía a pueblos más que a proyectos para abastecer ciudades, debido a que estos se encuentran más cercanos de los lugares donde es posible extraer biomasa. Otra posibilidad que se debe evaluar, es el uso de la biomasa en lugares que también permitan aprovechar el alto potencial calórico de la biomasa tales como, centros de comercio, hospitales, edificios, y eventualmente sistemas de calefacción distrital.

Las estimaciones de este estudio se basan en varios supuestos que representan una simplificación del ecosistema, lo cual produce algunas limitaciones. Por ejemplo, el tipo de cortas aplicadas (cortas intermedias y de regeneración), en algunos bosques en estado degradado podrían no ser aplicables, así como también los porcentajes de corta podrían ser mayores en otros casos. La estimación de la biomasa es potencial, ya que no se considera la disposición de parte de los propietarios a manejar los bosques. Otro aspecto que también se debería considerar como una variable a analizar y que no fue considerada en este estudio es la accesibilidad a las redes de transmisión eléctrica, lo cual tiene una fuerte incidencia en la instalación de una planta de generación de energía.

Los resultados muestran el potencial que tiene la biomasa del bosque nativo para generar energía eléctrica y calórica. En el área de estudio de este trabajo existe una gran proporción de bosques degradados, donde la madera de calidad (madera aserrada) no supera el 30\% definido (Reyes 2005), por lo tanto, es posible que hasta un $70 \%$ de la biomasa podría destinarse para fines energéticos (leña y otros usos). Por otra parte, la oferta de energía renovable de biomasa de bosques nativos está disponible a nivel local, reduce la dependencia en las importaciones de petróleo y gas, siendo además una fuente de energía carbono neutro.

Avances importantes en distintas materias se han desarrollado en el último tiempo que ayudan a disminuir la incertidumbre en las estimaciones de la biomasa forestal. Un ejemplo es el Explorador de Bioenergía Forestal (CONAF 2014), proyecto que dio origen a una plataforma virtual mediante la cual se hace disponible la información de la biomasa forestal para todo Chile. También representa un avance la sistematización y disponibilidad de parcelas permanentes de inventario del proyecto "Remedición y sistematización de información cuantitativa de parcelas permanentes en bosques de segundo crecimiento de roble, raulí y coigüe", financiado por el Fondo de Investigación del Bosque Nativo de CONAF. Otro aspecto que puede impactar de manera importante la exactitud de las estimaciones de biomasa es la degradación de los bosques. Algunos estudios señalan que la existencia de parches de bosques de menor tamaño podrían determinar una menor calidad del bosque debido a un mayor nivel de degradación (Echeverría et al. 2006). La calidad de los árboles, especialmente la pudrición, es un tema que ha sido estudiado y considerado en la estimación de volumen maderero, pero escasamente se ha estudiado su real efecto en la estimación de la biomasa y la consecuente generación de energía. Por ello, es de gran relevancia estudiar e incorporar la calidad de los bosques y árboles, en las futuras estimaciones de biomasa.

Otra de las ventajas de la biomasa del bosque nativo para uso energético, es que se promueve la economía local, generando valor agregado y ayudando a mantener la viabilidad de las áreas rurales. A su vez, la utilización de la biomasa implica un uso intensivo de mano de obra que beneficia a la comunidad local. Por lo tanto, la materialización de proyectos de este tipo podría generar altos impactos económicos, sociales y también ambientales. Schlatter y Thiers (2011) coinciden en plantear, que a través de una estrategia de manejo forestal, basado en la utilización de los bosques nativos, donde se incluya por cierto el objetivo dendroenergético, se podría lograr un desarrollo integral de la sociedad, es decir, producción forestal sostenible con base ecológica e influencia social. Respecto de los últimos, la aparición de nuevos proyectos que aumenten la demanda o mejoren los precios de la biomasa podría tener efectos como una mayor degradación o deforestación de los bosques. En muchos casos los propietarios utilizan el bosque nativo para el autoconsumo de leña y como refugio para sus animales domésticos, degradando sistemáticamente el recurso y no considerando el manejo sustentable como una alternativa. Esta situación genera incertidumbre respecto al abastecimiento constante y de largo plazo de biomasa para proyectos de cogeneración. Asimismo, un estudio detallado de la propiedad del bosque nativo, que considere aspectos como factibilidad de manejo y legalidad de la propiedad, sería una herramienta útil de planificación para disminuir la incertidumbre del suministro constante y de largo plazo de la biomasa, lo cual representa una de las barreras más importantes para la materialización de los proyectos.

\section{CONCLUSIONES}

El estado actual de los bosques nativos en el área de estudio, incorporando restricciones silviculturales, sociales y ambientales, permite un potencial uso adicional con fines dendroenergéticos, equivalente a 26 millones de MWh y 54 millones de MWh de energía eléctrica y térmica, respectivamente.

La disponibilidad potencial de biomasa y su equivalente en poder energético muestran fuerte relación con el tipo y estructura del bosque. Por su parte, la altitud del terreno explica la variación de la disponibilidad potencial de biomasa, relacionándose con características de sitio y con condiciones de accesibilidad; ambas relaciones involucran las tres principales unidades geomorfológicas del sur de Chile: Cordillera de la Costa, Depresión Intermedia y Cordillera de Los Andes.

Los diversos orígenes de los datos, la variación propia de los bosques nativos, la representatividad de los datos y las restricciones metodológicas aparecen como factores que limitan la precisión y exactitud de los resultados. Se propone seguir con este tipo de estudios, considerando explícitamente aspectos de escala espacial y temporal, así 
como aspectos de accesibilidad al uso potencial de la biomasa derivada de distintos tipos de cortas, con especial referencia a la calidad de biomasa. Un aspecto esencial a incluir son variables que representen las condiciones socioeconómicas de los propietarios de los terrenos y bosques, quienes finalmente incidirán sobre la intensidad y disponibilidad de la biomasa forestal con fines dendroenergéticos.

\section{AGRADECIMIENTOS}

El estudio fue financiado por el proyecto FONDEF D08I1056 y la Dirección de Investigación de la Universidad de La Frontera. Los autores agradecen el apoyo de Christian Salas, Víctor Rocco y Francoise Pincheira de la Universidad de La Frontera. También se agradece a los profesionales de la Universidad Austral de Chile Alicia Ortega, Pablo Donoso, Víctor Sandoval y Guillermo Trincado, quienes facilitaron diversas bases de datos para este trabajo.

Alejandro Miranda agradece a CONICYT/Programa Nacional de Doctorado/21140409.

\section{REFERENCIAS}

Altamirano A, A Lara. 2010. Deforestación en ecosistemas templados de la precordillera andina del centro-sur de Chile. Bosque 31(1): 53-64.

CASEN (Caracterización Socioeconómica Nacional, CL). 2006. Resultados última encuesta CASEN. Resultados energía. Consultado 5 sep. 2012. Disponible en http://observatorio.ministeriodesarrollosocial.gob.cl/casen_publicaciones. php?ano=2006

CER (Centro de Energías Renovables, CL). 2014. Reporte CER Julio 2014. Consultado 24 jul. 2014. Disponible en http://www.cer.gob.cl/mailing/2014/julio/REPORTE_Julio2014\%20FINAL.pdf

CNE (Comisión Nacional de Energía, CL).). 2011. Balance nacional de energía año 2010. Santiago, Chile. Consultado el 15 ene. 2013. Disponible en www.minenergia.gob.cl

CONAF (Corporación Nacional Forestal, CL). 2014. Sistema de Información Territorial de CONAF. Consultado el 18 ene. 2014. Disponible en http://sit.conaf.cl

CONAF (Corporación Nacional Forestal, CL). 2011. Catastro de los Recursos Vegetacionales Nativos de Chile. Monitoreo de cambios y actualizaciones. Período 1997-2011. Santiago, Chile. Corporación Nacional Forestal. 30 p.

CONAF, CONAMA, BIRF (Corporación Nacional Forestal, CL; Comisión Nacional del Medioambiente, CL; Banco Internacional de Reconstrucción y Fomento, US). 1999. Catastro y evaluación de los recursos vegetacionales nativos de Chile. Informe nacional con variables ambientales. Santiago, Chile.

Corvalán P. 1987. El Canelo: una alternativa de desarrollo para la Décima Región. Proyecto FIA. Santiago, Ministerio de Agricultura, Universidad de Chile, vol. I, II y III.

Donoso C. 1994. Bosques templados de Chile y Argentina. Variación estructura y dinámica. Santiago, Chile. Universitaria. $484 \mathrm{p}$.

Donoso C y A Lara. 1996. Utilización de los bosques nativos en Chile: Pasado, presente y futuro. Capítulo 19. In JJ Armes- to, C Villagrán y MK Arroyo eds. Ecología de los bosques nativos de Chile. Monografías. Santiago, Chile. Universitaria. p. 363-387.

Donoso P. 1988. Caracterización y proposiciones silviculturales para renovales de Roble (Nothofagus obliqua) y Raulí (Nothofagus alpina) en el área de protección "Radal 7 Tazas", VII Región. Bosque 9(2): 103-114.

Echeverría C, D Coomes, J Salas, JM Rey-Benayas, A Lara, A Newton. 2006. Rapid deforestation and fragmentation of chilean temperate forests. Biological Conservation 130: 481-494.

Echeverría C, A Lara. 2004. Growth patterns of secondary Nothofagus obliqua-N. alpina forests in southern Chile. Forest Ecology and Management 195: 29-43.

ENDESA (Empresa Nacional de Electricidad, CL). 2012. Centrales Generadoras. Consultado el 23 ago. 2012. Disponible en http://www.endesa.cl/Endesa_Chile/action.asp?id=11000

Esse C, PJ Donoso, V Gerding, F Encina-Montoya. 2013. Determination of homogeneous edaphoclimatic zones for the secondary forest of Nothofagus dombeyi in central-southern Chile. Ciencia e Investigación Agraria 40: 351-360.

Gayoso J, J Guerra, D Alarcón. 2002. Proyecto FONDEF: Medición de la capacidad de captura de carbono en bosque de Chile y promoción en el mercado mundial. Contenido de carbono y funciones de biomasa en especies nativas y exóticas. Universidad Austral de Chile e Instituto Forestal (INFOR). Informe Técnico. 53 p.

INE (Instituto Nacional de Estadísticas, CL). 2005. Chile: ciudades, pueblos, aldeas y caseríos. Santiago, Chile. Departamento de Geografía y Censos. 300 p.

INFOR (Instituto Forestal, CL). 2009. Los recursos forestales en Chile. Inventarios contínuos de bosques nativos y actualización de plantaciones forestales. INFOR. 202 p.

INFOR (Instituto Forestal, CL). 2011. Los Recursos Forestales en Chile. Inventario continuo de bosques nativos y actualización de plantaciones forestales. Informe final. 297 p.

INFOR (Instituto Forestal, CL). 2012. Boletín estadístico 136. Anuario Forestal 2012. Daniel Soto (ed.). Santiago, Chile. INFOR. 138 p.

Lara A, V Sandoval, V Gerding, C Donoso. 1999. Estudio técnico de propuesta de Silvicultura y Manejo Forestal para la Nueva Planta de Tableros OSB. Proyecto BOMASIL UACh. Informe Final. Valdivia, Chile. Universidad Austral de Chile. 89 p.

Lara A, C Little, C Echeverría, M Cortés, L Otero, O Thiers. 2006. Evaluación de normas de manejo aplicadas a renovales de RORACO. Estudio técnico de propuesta de silvicultura y manejo forestal para la nueva planta de tableros OSB Lautaro. Informe Final. Valdivia, Chile. Universidad Austral de Chile.

Lara A, R Reyes, R Urrutia. 2013. Bosques nativos. In Centro de Análisis de Políticas Públicas, Universidad de Chile eds. Informe País: Estado del Medio Ambiente en Chile 2013. Santiago, Chile. Nova Graf. p. 145-188.

Lu D, Q Weng. 2007. A survey of image classification methods and techniques for improving classification performance. International Journal of Remote Sensing 28(5): 823-870.

Meléndez JM, M Torres. 2007 La biomasa forestal, su importancia en la provincia de Guadalajara. Revista Forestal 34: 50-57.

Milla F, P Emanuelli, A Sartori. 2013. Compendio de funciones 
alométricas para la estimación de biomasa de especies forestales presentes en Chile: Elemento clave para la Estrategia Nacional de Bosques y Cambio Climático (ENBCC). Corporación Nacional Forestal. 556 p.

Paneque M, C Román-Figueroa, R Vázquez-Panizza, JM Arriaza, D Morales, M Zulantay, M. 2011. Bioenergía en Chile. Paneque M. (eds.). Organización de las Naciones Unidas para la Alimentación y la Agricultura, Facultad de Ciencias Agronómicas, Universidad de Chile. 124 p.

Pérez V. 1983. Manual de propiedades físicas y mecánicas de maderas chilenas. Proyecto CONAF/PNUD/ FAO-CHI 76/003. Santiago, Chile. Documento de Trabajo No 47. 451 p.

Pilquinao B. 2013. Variación de la biomasa aérea y el potencial energético en bosques de los tipos forestales roble-raulícoigüe y siempreverde en el centro-sur de Chile. Magíster en Ciencias Mención Recursos Forestales. Escuela de Graduados de Ciencias Forestales. Facultad de Ciencias Forestales y Recursos Naturales, Universidad Austral de Chile. 76 p.

Pontt C. 2008. Potencial de biomasa en Chile. Universidad Técnica Federico Santa María (UTFSM). Valparaíso, Chile. 74 p.

Reyes R. 2005. Leña: una oportunidad para la conservación de los bosques templados del sur de Chile. Bosque Nativo 37: 16-23. Schlatter JE, O Thiers. 2011. El Sector Forestal en la región de Los Ríos: Una visión productiva con base ecológica e influencia social. Bosque Nativo 49: 26-27.

Schlegel B. 2001. Estimación de la biomasa y carbono en bosques del tipo forestal siempreverde. Simposio Internacional Medición y Monitoreo de la Captura de Carbono en Ecosistemas Forestales, 18 al 20 de Octubre del 2001 Valdivia - Chile. 13 p.

Schulz J, L Cayuela, C Echeverria, J Salas, JM Rey Benayas. 2010. Monitoring land cover changes of dryland forest landscape of Central Chile (1975, 2008). Applied Geography 30(3): 436-447.

Torrez-Álvarez O, F Peña-Cortez. 2011. Zonificación del potencial energético de la biomasa residual forestal en la cuenca del lago Ranco, Chile, Antecedentes para la planificación energética regional. Bosque 32(1): 77-84.

Universidad de Chile, Universidad Técnica Federico Santa María. 2008. Aporte potencial de: Energías renovables no convencionales y eficiencia energética a la matriz eléctrica, 2008-2025. 21 p. Consultado el 13 de Septiembre de 2012. Disponible en http://www.neim.utfsm.cl/arch/ERNC.pdf.

Recibido: 13.08 .14

Aceptado: 10.03.15 
